\title{
CORRELAÇÃO DO CONHECIMENTO NUTRICIONAL E OS NÍVEIS SÉRICOS DE POTÁSSIO E FÓSFORO EM PACIENTES SUBMETIDOS À HEMODIÁLISE
}

\author{
CORRELATION OF NUTRITIONAL KNOWLEDGE WITH SERUM \\ POTASSIUM AND PHOSPHORUS LEVELS IN PATIENTS SUBMITTED \\ TO HEMODIALYSIS
}

\author{
Andreza Silva Pereira ${ }^{1}$ \\ Cândida Maria de Figueiredo Martins ${ }^{2}$ \\ Barbara Costa Paulino ${ }^{3}$ \\ Carolina Moreira de Santana ${ }^{4}$
}

RESUMO: Objetivo: Avaliar o nível de conhecimento nutricional e sua correlação com os níveis séricos de potássio e fósforo dos pacientes com Insuficiência Renal Crônica submetidos à hemodiálise. Método: Estudo do tipo descritivo, observacional e transversal com abordagem quantitativa, realizado na Cidade de Cajazeiras, Paraíba. Participaram da pesquisa, indivíduos adultos, de ambos os sexos com faixa etária entre 20 a 59 anos de idade, com Insuficiência Renal Crônica que estivessem realizando hemodiálise na cidade de Cajazeiras/PB. Os dados foram coletados utilizando uma ficha clínica com informações sobre os dados pessoais, clínicos e bioquímicos e um questionário de avaliação do conhecimento nutricional. $A$ análise dos dados foi feita com estatística descritiva e com o teste de correlação de Spearman, adotando a significância estatística de $5 \%$, ou seja, $p<0,05$. Resultados: Observou-se que dos 33 indivíduos envolvidos na pesquisa, 54,55\% ( $n=18)$ eram do sexo masculino, com média de idade e tempo de hemodiálise de 42,75 $\pm 10,10$ e $4,12 \pm 3,36$ anos respectivamente. Dentre as patologias mais prevalentes estão a hipertensão arterial sistêmica $(72,73 \%)$ e o Diabetes mellitus $(18,18 \%)$. Sobre os dados bioquímicos, a média do potássio e de fósforo foi de $5,52 \pm 0,81 \mathrm{mEq}$ e $5,69 \pm 1,79 \mathrm{mg}$, respectivamente, mostrando-se inadequados. Quanto à análise do conhecimento nutricional, as perguntes visavam relacionar o grau de conhecimento. Diante disto, pôde-se observar que $12,12 \%$ mostraram ter baixo conhecimento,

\footnotetext{
${ }^{1}$ Nutricionista graduada pela Faculdade Santa Maria, Paraíba, Brasil.

2 Nutricionista graduada pela Faculdade Santa Maria, Paraíba, Brasil.

${ }^{3}$ Mestre em Nutrição pela Universidade Federal de Pernambuco; Docente do Curso de Bacharelado em Nutrição da Faculdade Santa Maria, Paraíba, Brasil.

4 Mestre em Sistema Agroindustriais pela Universidade Federal de Campina Grande (UFCG); Docente do Curso de Bacharelado em Nutrição da Faculdade Santa Maria, Paraíba, Brasil.
} 
$51,52 \%$ moderado e $36,36 \%$ alto conhecimento nutricional. Portanto, de acordo com a análise do conhecimento nutricional e dos níveis séricos de potássio e fósforo, constatou-se uma correlação significativa entre o potássio e o conhecimento nutricional $(p=0,02)$. Conclusão: Conclui-se que quanto maior for o conhecimento nutricional, melhor serão os valores séricos de potássio, contribuindo para melhora do quadro clínico. Por outro lado, o conhecimento nutricional não demonstrou relação com os níveis séricos de fósforo. Sendo assim. Estudos como este são de suma importância para proporcionar um aconselhamento dietético direcionado à realidade de vida dos indivíduos, ajudando a reduzir os agravos que surgem na Insuficiência Renal Crônica.

Palavras chave: Insuficiência renal crônica. Nutrição. Hemodiálise.

ABSTRACT: Objective: To assess the level of nutritional knowledge and its correlation with the serum levels of potassium and phosphorus in patients with Chronic Kidney Failure undergoing hemodialysis. Method: Descriptive, observational and cross-sectional study with a quantitative approach, conducted in the City of Cajazeiras, Paraiba. Participated in the research, adult individuals, of both sexes, aged between 20 and 59 years old, with Chronic Kidney Failure who were undergoing hemodialysis in the city of Cajazeiras / PB. The data were collected using a clinical form with information on personal, clinical and biochemical data and a questionnaire to assess nutritional knowledge. Data analysis was performed using descriptive statistics and the Spearman correlation test, adopting a $5 \%$ statistical significance, that is, $p<0.05$. Results: It was observed that of the 33 individuals involved in the research, $54.55 \%(n=18)$ were male, with a mean age and hemodialysis time of $42.75 \pm$ 10.10 and $4.12 \pm 3.36$ years respectively. Among the most prevalent pathologies are systemic arterial hypertension (72.73\%) and Diabetes mellitus (18.18\%). Regarding the biochemical data, the average of potassium and phosphorus was $5.52 \pm 0.81 \mathrm{mEq}$ and $5.69 \pm$ $1.79 \mathrm{mg}$, respectively, proving to be inadequate. As for the analysis of nutritional knowledge, the questions aimed to relate the degree of knowledge. In view of this, it was observed that $12.12 \%$ showed low knowledge, 51.52\% moderate and $36.36 \%$ high nutritional knowledge. Therefore, according to the analysis of nutritional knowledge and serum levels of potassium and phosphorus, a significant correlation was found between potassium and nutritional knowledge $(p=0.02)$. Conclusion: It is concluded that the higher the nutritional knowledge, the better the serum potassium values, contributing to the improvement of the clinical picture. On the other hand, nutritional knowledge has not shown a relationship with serum phosphorus levels. Studies like this are extremely important to provide dietary advice directed to the reality of individuals' lives, helping to reduce the problems that arise in Chronic Kidney Failure.

Keywords: Chronic Renal Failure. Nutrition. Hemodialysis. 


\section{INTRODUÇÃO}

A Doença Renal Crônica (DRC) é considerada um grave problema em saúde pública e é determinada pela perda gradual e irreversível das funções renais (CLEMENTINO et al., 2014). A DRC tem apresentado elevada prevalência e incidência, bem como um alto custo para seu diagnóstico e tratamento. Além disso, está constantemente relacionada aos índices de redução da qualidade de vida dos indivíduos afetados, devido aos problemas metabólicos e hormonais (DOBNER et al., 2014).

A DRC é subdividida em cinco fases, conforme o andamento da Taxa de Filtração Glomerular (TFG) e agravamento da enfermidade. O quinto e último estágio é classificado como Insuficiência Renal Crônica (IRC), no qual ocorre o dano renal terminal, sendo necessária uma terapia renal substitutiva (TRS) (SILVA; MURA; BRITO et al., 2016).

Após a confirmação do diagnóstico de IRC o indivíduo é submetido a uma das formas de TRS, como a diálise peritoneal, a hemodiálise (HD) e o transplante renal (TEIXEIRA et al., 2015). A HD é considerada uma terapia invasiva que consiste em um processo mecânico que promove a retirada de substâncias tóxicas do organismo, sendo, geralmente, realizada três vezes por semana, em dias intercalados, onde cada sessão tem duração de aproximadamente três a quatro horas (PAULA et al., 2017; SILVA; MAYA; MOREIRA 2017).

Durante o tratamento com a HD, é fundamental que haja conhecimento dos alimentos que podem ser ingeridos, de modo que o conhecimento nutricional pode contribuir significativamente para a mudança de comportamento no tratamento da patologia (BARBOSA et al., 2016).

Neste contexto, é fundamental que haja uma avaliação nutricional completa, especialmente em relação aos dados bioquímicos, sendo os principais o hemograma, a albumina, creatinina e ureia, além dos níveis séricos de potássio e 
fósforo, tendo em vista que podem sofrer influências dos distúrbios relacionados à IRC (CUPPARI, 2014; ROUHANI et al., 2017).

O fósforo é um elemento essencial e bem atuante no desempenho celular, por outro lado, o potássio age juntamente com o sódio, na manutenção do equilíbrio acidobásico, por meio da bomba de sódio e potássio (FRIZZERA, 2013). A hiperfosfatemia, ou seja, a elevação nos níveis séricos de fósforo, ocasiona implicações sérias podendo aumentar de forma expressiva a morbimortalidade dos indivíduos com IRC (ARAUJO et al., 2015). Por isso, é fundamental que haja um controle do fósforo dietético, embora seja impossível retirar o fósforo completamente, já que os mesmos alimentos são fontes de proteínas e cálcio importantes para o corpo. Ressalta-se, que o fósforo é parcialmente retirado na HD e também os pacientes em tratamento hemodialítico utilizam quelantes de fósforo evitando a sua absorção (TELLES; BOITA, 2015).

A hiperpotassemia caracterizada pelo aumento nos níveis séricos de potássio (TELLES; BOITA, 2015) também é comum em indivíduos com IRC, podendo causar efeitos no miocárdio, e, em situações mais graves, leva a fraqueza do músculo, bem como sintomas como náuseas, cólica intestinal e diarreia (CALVACANTI et al., 2015).

Portanto, com base na significância da orientação nutricional, do conhecimento dos hábitos alimentares e do estado nutricional, o objetivo deste estudo foi avaliar o nível de conhecimento nutricional e sua correlação com os níveis séricos de potássio e fósforo dos pacientes com IRC submetidos à hemodiálise

\section{METODOLOGIA}

Este estudo se caracteriza como descritivo, observacional e transversal com abordagem quantitativa, realizado na Cidade de Cajazeiras-PB e faz parte do projeto de pesquisa intitulado "Avaliação da correlação entre a farmacoterapia, perfil e conhecimento nutricional com os exames bioquímicos de pacientes submetidos à 
hemodiálise em uma cidade do alto sertão paraibano", aprovado no Comitê de Ética em Pesquisa da Faculdade Santa Maria (FSM), com parecer favorável n 2.516.785.

A população estudada consistiu em um grupo de indivíduos adultos, na faixa etária de 20 a 59 anos de idade, de ambos os sexos, portadores de IRC que frequentam o Centro de Hemodiálise de Cajazeiras três vezes na semana e que possuíam as informações referentes aos dados bioquímicos hemoglobina, albumina, ureia, creatinina, potássio e fósforo no prontuário no decorrer dos últimos três meses.

Sendo assim, utilizando essas informações foram excluídos da pesquisa os indivíduos menores de 20 anos e maiores de 60 anos, os que não deambulavam, aqueles que entraram no centro de hemodiálise recentemente e os indivíduos portadores de problemas cognitivos que não conseguiram responder o questionário de conhecimento nutricional, bem como, os que não tiveram informações sobre os dados bioquímicos (hemoglobina, albumina, ureia e creatinina) e níveis séricos de potássio e fósforo no prontuário como delineado nos critérios de inclusão.

Do total de 84 indivíduos que frequentam a hemodiálise foram selecionados 43 pacientes, entretanto ao serem avaliados, cinco (05) foram excluídos por não aceitarem fazer parte da pesquisa e cinco (05) por terem sido admitidos recentemente, não sendo possível, obter os dados dos exames bioquímicos (albumina e creatinina são avaliados a cada dois meses). Logo, participaram da pesquisa 33 pacientes que frequentam o Centro da Hemodiálise da cidade de Cajazeiras- PB.

A coleta de dados iniciou com a explicação dos procedimentos que seriam realizados e solicitando a autorização dos participantes da pesquisa por meio da assinatura do Termo de Consentimento Livre e Esclarecido, obedecendo a todos os preceitos éticos (BRASIL, 2012) e sendo realizada entre os meses de março a maio de 2018, nos turnos matutino, vespertino e noturno em concordância com as datas e horários acordados pelo responsável e participantes do centro de hemodiálise.

O instrumento de coleta de dados continha informações pessoais (código de identificação, data de nascimento, idade, sexo, profissão, renda familiar, grau de escolaridade), dados clínicos (patologias atuais ou pregressas, há quanto tempo faz hemodiálise, alergia ou intolerância alimentar, alterações gastrointestinais), questões 
referentes ao conhecimento nutricional, todos estas coletadas diretamente com os participantes da pesquisa. Além disso, foram coletadas informações nos prontuários dos participantes, referentes aos dados bioquímicos (hemograma, albumina, ureia e creatinina, níveis séricos de fósforo e potássio), no decorrer dos últimos três meses.

As questões referentes à avaliação do conhecimento nutricional, desenvolvidas pelos pesquisadores, era composto por dez perguntas objetivas, simples e de fácil aplicabilidade concernente ao grau de conhecimento dos seguintes itens: a alimentação em relação ao tratamento da IRC; importância do consumo adequado de sódio, fósforo e potássio, bem como, do consumo de proteínas; causas da elevação da hiperpotassemia; alimentos que tem maior quantidade de proteínas; alimento que não deve ser consumido na IRC; qual alimento é rico em fósforo; alimento que deve ser consumido com moderação devido ao elevado teor de potássio; técnica de cocção utilizado para reduzir o teor de potássio.

Logo, a análise das respostas do questionário foi realizada através da atribuição de pontuação para cada item (1,0 ponto), podendo totalizar, no máximo, 10 pontos, caso todas as questões estejam respondidas corretamente. Sendo assim, o conhecimento nutricional de cada indivíduo foi considerado: baixo (0 a 4 pontos), moderado (5 a 7) e alto (acima de 8), sendo essa escala para classificação do conhecimento nutricional elaborada pelo próprio pesquisador.

O processamento dos dados foi realizado por meio do Microsoft Exce/ß 2016 para a construção do banco de dados e a análise foi realizada no software MiniTabß. Realizou-se a análise descritiva dos dados, com cálculo das frequências e aplicação do teste de normalidade de Kolmogorov-Smirnov para avaliação da aderência das variáveis quantitativas à distribuição normal. Em seguida, foi aplicado o teste de correlação de Spearman, adotando a significância estatística de $5 \%$, ou seja, $p<0,05$. 


\section{RESULTADOS}

A pesquisa teve participação de 33 indivíduos submetidos ao tratamento de HD da Cidade de Cajazeiras- PB, sendo $54,55 \%(n=18)$ do sexo masculino e $45,45 \%(n=15)$ do sexo feminino, com média de idade de $42,75 \pm 10,10$ anos. Quanto à renda familiar, $87,28 \%(n=29)$ relataram ter entre 1 a 2 salários mínimos, e apenas $12,12 \%(n=4) 3$ ou mais salários mínimos.

Dentre as patologias mais prevalentes nos participantes da pesquisa estão a hipertensão arterial sistêmica (HAS) em 72,73\% ( $n=24)$ e o Diabetes mellitus (DM) em $18,18 \%(n=6)$ dos indivíduos, contudo, foi observado ainda que 6,06\% ( $n=2)$ possuíam intolerância à lactose, azia (42,42\%), refluxo (24,24\%), vômitos/náuseas $(21,21 \%)$ e constipação $(15,15 \%)$, além de diarreia $(6,06 \%)$ e disfagia $(3,03 \%)$.

$\mathrm{Na}$ atual pesquisa, os níveis de potássio foram classificados em hipopotassemia, normopotassemia e hiperpotassemia. Entretanto, nenhum indivíduo apresentou hipopotassemia, enquanto $21,21 \%(n=7)$ apresentaram níveis normais e $78,79 \%(n=26)$ apresentaram hiperpotassemia. Por outro lado, os níveis de fósforo foram classificados em hipofosfatemia, normofosfatemia e hiperfosfatemia. Sendo que $9,09 \% \quad(n=3)$ dos indivíduos apresentaram hipofosfatemia, 42,42\% $(n=14)$ normofosfatemia e 48,48\% (n=16) hiperfosfatemia. Os resultados referentes aos dados bioquímicos avaliados foram expressos em média e desvio padrão, e apresentados na tabela 1 . 
Tabela 1: Resumo das médias de hemoglobina para ambos os sexos, albumina, ureia pré e pós, creatinina, potássio e fósforo dos indivíduos submetidos a hemodiálise.

\begin{tabular}{lccc}
\hline \multicolumn{1}{c}{ Exames } & Valores de referência & Média & Desvio padrão \\
\hline Hemoglobina - Homens $(\mathrm{g} / \mathrm{dL})$ & $>13,0$ & 11,53 & 1,81 \\
Hemoglobina - Mulheres $(\mathrm{g} / \mathrm{dL})$ & $>12,0$ & 11,32 & 1,84 \\
Albumina* $(\mathrm{g} / \mathrm{dL})$ & $>4,0$ & 3,88 & 0,32 \\
Ureia Pré $(\mathrm{mg} / \mathrm{dL})$ & $14-40$ & 138,63 & 38,79 \\
Ureia Pós** $(\mathrm{mg} / \mathrm{dL})$ & $14-40$ & 8,00 & 10,00 \\
Creatinina $(\mathrm{mg} / \mathrm{dL})$ & $1-2$ & 10,44 & 3,24 \\
Potássio $(\mathrm{mEq})^{* * *}$ & $3,5-5,0$ & 5,52 & 0,81 \\
Fósforo $(\mathrm{mg} / \mathrm{dL})$ & $3,5-5,5$ & 5,69 & 1,79 \\
\hline
\end{tabular}

Fonte: Dados da pesquisa, Cajazeiras - PB, 2018.

* Os cálculos da média foram realizados com 31 indivíduos, pois 2 participantes não tinha os valores de albumina.

** Os cálculos da média foram realizados com 32 indivíduos, pois 1 participante não tinha os valores de um mês de ureia-pós HD.

*** Os cálculos da média foram realizados com 31 indivíduos, pois 2 participantes não tinha os valores referente a um mês de potássio.

Os resultados referentes ao conhecimento nutricional foram classificados em baixo, moderado e alto conhecimento, constatando-se que $12,12 \% \quad(n=4)$ dos indivíduos participantes da pesquisa mostraram ter baixo conhecimento, 51,52\% $(n=17)$ tiveram moderado e $36,36 \% \quad(n=12)$ apresentaram alto conhecimento nutricional.

Os resultados do teste de correlação de Spearman estão expressos na tabela 2. 
Tabela 2: Correlação estatística entre potássio e conhecimento nutricional dos indivíduos submetidos a hemodiálise.

\begin{tabular}{|c|c|c|c|}
\hline \multicolumn{4}{|c|}{ CORRELAÇÃO ENTRE VARIÁVEIS DO ESTUDO ( $\mathrm{N}=33$ ) } \\
\hline & & $\begin{array}{c}\mathbf{R} \\
033\end{array}$ & Valor de $\mathbf{p}$ \\
\hline Escore de Fósforo & Conhecimento Nutricional & 0,11 & 0,25 \\
\hline
\end{tabular}
$(p<0,05)$

Observa-se que houve correlações estatisticamente significativas entre o potássio e o conhecimento nutricional $(p=0,02)$, porém, não houve correlação com o fósforo.

\section{DISCUSSÃO}

O perfil epidemiológico traçado nessa pesquisa também condiz com o Censo de Diálise da Sociedade Brasileira de Nefrologia (2013), onde verificou-se que a maioria dos pacientes era do gênero masculino. Portanto, várias análises sugerem que os homens se tornam mais suscetível à essa enfermidade do que as mulheres, tendo em vista que eles procuram menos os serviços de saúde em comparação as mulheres que são mais participativas (CLEMENTINO et al., 2014).

A faixa etária mínima encontrada neste estudo foi de 24 anos e a máxima de 58 anos, este fato pode estar associado ao surgimento dos grupos de risco e das doenças de base para a o desenvolvimento da IRC, outros estudos associaram que a causa para o surgimento da IRC nessa faixa etária era possivelmente devido às altas prevalências de doenças de base nesses indivíduos (ALVES et al., 2017).

A maioria dos indivíduos participantes deste estudo relatou ter renda familiar entre 1 e 2 salários, sendo esta decorrente, na maioria dos casos, de benefícios da aposentadoria associada ao auxílio-doença. Fato este que também foi analisado no estudo de Oliveira Júnior, Formiga e Alexandre (2014) em que a remuneração 
familiar mensal dos pacientes era em média de dois salários mínimos, provindos praticamente do auxílio disponibilizado pela previdência social.

A respeito da prevalência da HAS encontrada na pesquisa, um estudo realizado por Alves, Bastos e Silva (2014) também encontrou essa prevalência, sendo observado em $62,9 \%$ dos indivíduos. Da mesma forma, Montenegro et al. (2015) e Schuster et al. (2015) observaram, respectivamente, que 76,6\% e 79,4\% dos indivíduos submetidos ao tratamento de hemodiálise tinham HAS.

Contudo, apesar do DM ser citada por apenas 18,18\% da amostra, é, assim como a HAS, uma importante causa de risco para o desenvolvimento de dano renal e progressão para IRC (COUTO et al., 2017). A incidência de HAS aumenta cada vez mais à medida que a função renal se prejudica, diante disto, na fase dialítica, grande parte dos nefropatas são hipertensos, favorecendo para o agravo do risco de morte cardiovascular (DOBNER et al., 2014).

Conforme os resultados dos dados bioquímicos, os valores de hemoglobina podem ser comparados com o estudo de D'Amico et al. (2013) que observaram que os 35 pacientes, estudados por eles, apresentaram média de hemoglobina abaixo do preconizado, tanto para o sexo masculino $(10,77 \pm 1,69 \mathrm{~g} / \mathrm{dL})$, quanto para o sexo feminino $(10,46 \pm 1,73 \mathrm{~g} / \mathrm{dL})$, podendo apontar a existência de anemia, de acordo com os parâmetros estabelecidos ( $<13 \mathrm{~g} / \mathrm{dL}$ para homens e $<12 \mathrm{~g} / \mathrm{dL}$ para mulheres) por Ribeiro-Alves e Gordan (2014) na atualização da diretriz para o tratamento de anemia na DRC. O estudo de Kock, Neto e Machado (2017) observou que 74 indivíduos $(60,6 \%)$ do sexo masculino apresentaram valores de $11,9 \pm 2,7 \mathrm{~g} / \mathrm{dL}$ e 48 indivíduos $(39,4 \%)$ do sexo feminino apresentaram $10,9 \pm 2,3 \mathrm{~g} / \mathrm{dL}$ da hemoglobina, indicando do mesmo modo, anemia.

A alta prevalência de anemia em indivíduos com DRC pode estar relacionada a redução nos níveis de eritropoetina, um hormônio produzido nos rins que estimula a produção de hemácias (HAZIN, 2020).

Os valores de albumina podem ser comparados com o estudo concretizado por Alvarenga et al. (2017), em que apresentou uma média de albumina $3,83 \pm 0,28 \mathrm{~g} / \mathrm{dL}$. Na pesquisa de Ribeiro et al. (2015) o valor de albumina encontrado foi de $3,9 \pm 0,4 \mathrm{~g} / \mathrm{dL}$, ao contrário de Ferraz et al. (2015) que constatou que a 
população estudada apontou em média níveis adequados para a albumina, com $64 \%$ dos pacientes apresentando valores de $4,1 \pm 0,3 \mathrm{~g} / \mathrm{dL}$.

A albumina sérica tem sido um parâmetro comumente empregado como marcador do estado nutricional de indivíduos em HD, devido a Desnutrição Energética Proteica ocasionar redução na sua síntese. Porém, esta proteína plasmática não deve ser usada como critério único, já que fatores como idade, comorbidade, perdas corpóreas e outros, intervém em suas concentrações séricas (ALVARENGA et al., 2017).

A ureia é outro marcador bioquímico e no estudo de Tinôco et al. (2018) os valores apresentados de ureia pré e pós HD, são respectivamente $169,7 \pm 35,3$ e $54,7 \pm 14,6$ onde $56,5 \%$ estavam alteradas. A ureia é um composto decorrente da degradação das proteínas e nos casos IRC tende a se concentrar no sangue fator este que dá origem aos episódios de uremia, visto que o mesmo tem sua concentração sérica elevada à medida que a TFG diminui (ARCARI et al., 2016).

Em relação à creatinina, a média dos resultados do presente estudo pode ser comparada com resultados da pesquisa de Nunes et al. (2014) em que a creatinina

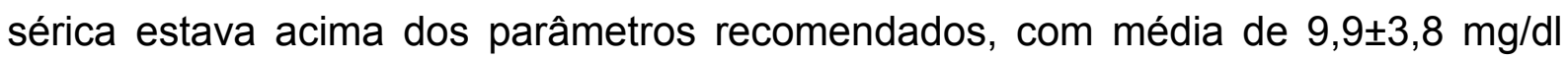
( $\geq 10 \mathrm{mg} / \mathrm{dL})$. Já no estudo de Kock, Neto e Machado (2017), e no Tinôco et al. (2018) os valores encontrados foram de $10,1 \pm 4,1 \mathrm{mg} / \mathrm{dL}$ e $11,1 \pm 3,5 \mathrm{mg} / \mathrm{dl}$ respectivamente, considerados altos. Ressalta-se que o uso da creatinina sérica isolada não é recomendado como marcador precoce de lesão renal (ALVES et al., 2017), pois os seus níveis plasmáticos só aumentam quando a função renal já está bastante debilitada (MASSEY, 2004). Por isso, a creatinina não é considerada um marcador sensível para a avaliação da lesão renal em estágios iniciais (PORTO et al., 2017).

A hiperfosfatemia foi observada em 48,48\% dos indivíduos neste estudo, semelhante ao verificado por Melo, Elias e Aguiar (2019) em que mais da metade dos indivíduos em HD apresentaram hiperfosfatemia apesar das orientações nutricionais e plano alimentar individualizado. Ressalta-se que esta condição aumenta a morbidade e mortalidade em indivíduos em HD (CARVALHO; CUPPARI, 2011).

Quanto ao conhecimento nutricional dos participantes desta pesquisa, os resultados são semelhantes aos do estudo realizado por Frizzera (2013) que em um 
dos questionários aplicados, o intuito era avaliar o grau de conhecimento de participantes submetidos à HD em relação a alguns nutrientes e cerca de $77,06 \%$ das questões estavam corretas e $22,94 \%$ estavam erradas.

Em relação à distribuição em percentuais da classificação do conhecimento nutricional dos indivíduos submetidos a hemodiálise, embora não haja estudos sobre conhecimento nutricional de pacientes renais, um estudo realizado por Fukuda, Mendonça e Lopes (2013) com 109 indivíduos portadores de doenças crônicas não transmissíveis, observou o conhecimento nutricional, por meio de um questionário, onde $69,72 \%$ apresentou um médio conhecimento, $23,85 \%$ tinham baixo conhecimento e apenas $6,42 \%$ possuíam um alto conhecimento em questões relacionadas à nutrição e alimentação saudável.

No que diz respeito a correlação apresentada entre os níveis séricos de potássio e o conhecimento nutricional dos indivíduos submetidos a hemodiálise nesta pesquisa, assemelha-se ao estudo de Nerbass et al. (2017) em que foram encontradas correlações diretas entre os escores de conhecimento do paciente e entre seus níveis plasmáticos. Entretanto, essa parte ainda é muito escassa de estudos que avaliam o nível de conhecimento nutricional através de instrumentos validados.

Por outro lado, a não correlação do fósforo com o conhecimento nutricional pode estar relacionada à abundância deste mineral na alimentação, independendo assim, do conhecimento. Resultados semelhantes foram observados por Nerbass et al. (2010) que não encontraram relação entre o nível de conhecimento, sendo este, analisado por pontuação total e por questão com as concentrações de fósforo do público avaliado. Contudo, segundo o autor ainda existem controvérsias sobre a relação entre informação e conhecimento, além da aceitação as terapias dietéticas e medicamentosas de pacientes em diálise. 


\section{CONCLUSÃO}

Concluiu-se que há correlação significativa entre o potássio e o conhecimento nutricional, pois quanto maior for o conhecimento nutricional, melhor serão os valores séricos de potássio, contribuindo para melhora do quadro clínico. Por outro lado, neste estudo, o fósforo não apresentou relação com o conhecimento nutricional.

Portanto, torna-se necessário a concretização de mais estudos que busquem identificar e esclarecer melhor sobre esse quesito, haja visto que no Brasil são escassos os estudos que utilizam a presente escala para avaliação do conhecimento nutricional e a correção com esse micronutriente.

Dessa forma, é perceptível que estudos como esse apresentado são de suma importância para conhecer o problema e assim, proporcionar um aconselhamento dietético direcionado à realidade de vida dos indivíduos, ajudando a reduzir os índices de hiperpotassemia e consequentemente os episódios e agravos que surgem na IRC, além de incentivar e conscientizar a aderir as estratégias nutricionais.

\section{REFERÊNCIAS BIBLIOGRÁFICAS}

ALVARENGA, L. A. et al. Análise do perfil nutricional de pacientes renais crônicos em hemodiálise em relação ao tempo de tratamento. Revista Jornal Brasileiro de Nefrologia, $v$. 39, n. 3, p. 283-286, 2017.

ALVES, A. B.; BASTOS, D. P.; SILVA, D. A. Avaliação da comorbidade entre hipertensão arterial sistêmica e insuficiência renal. Revista Acta Biomédica Brasiliensia, v. 5, n. 2, p. 4959, dez. 2014.

ALVES, M. A. R.; GORDAN, P. A. Diagnóstico de anemia em pacientes portadores de doença renal crônica. Jornal Brasileiro de Nefrologia, v. 4, n. 36 (1 Supl. 1), p. 9-12, 2014.

ALVES, L. F. et al. Prevalência da doença renal crônica em um município do sudeste do Brasil. Jornal Brasileiro de Nefrologia, v. 39, n. 2, p. 126-134, 2017.

ARAUJO, E. K. R. Consequências da hiperfosfatemia em pacientes renais crônicos em programas de hemodiálise: uma revisão integrativa. Revista e-ciência, v. 3, n. 2, p. 107-116, 2015.

ARCARI, I. et al. Avaliação de biomarcadores renais e adenosina deaminase salivar em 
pacientes com doença renal na pré e pós-hemodiálise. Unoesc e Ciência - ACBS. Joaçaba, $v$. 7, n. 2, p. 125-130, jul/dez. 2016.

BARBOSA, L. B. et al. Estudos de avaliação do conhecimento nutricional de adultos: uma revisão sistemática. Ciência e Saúde Coletiva, v. 21, n. 2, p. 449-462, 2016.

BRASIL. Conselho Nacional de Saúde. Resolução n 466, de 12 de dezembro de 2012. Aprova normas regulamentadoras de pesquisas envolvendo seres humanos. Brasília: Diário Oficial da União, 2012.

BRITO, A. C. D. et al. Conhecimento de hiperfosfatemia e quelante de fósforo em hemodialíticos. BRASPEN Journal. São Luís, v. 31, n. 4, p. 322-328, 2016.

CAVALCANTI, M. I. C. D. F. et al. Pacientes em hemodiálise com diagnóstico de enfermagem volume de líquidos excessivo: aspectos socioeconômicos e clínicos. Cogitare Enfermagem. V. 20, n. 1, p. 61-70, jan/mar. 2015.

CARVALHO, A. B.; CUPPARI, L. Controle da hiperfosfatemia na DRC. Jornal Brasileiro de Nefrologia, v. 33, n. 2, S1-S6, 2011.

CLEMENTINO, A. V. et al. Avaliação Nutricional de Pacientes com Insuficiência Renal Crônica Submetidos à Hemodiálise em uma Clínica de Nefrologia em João Pessoa-PB. Revista Brasileira de Ciências da Saúde, v.18, n. 4, p. 287-296, 2014.

COUTO, K. G. et al. Prevalência de casos de Insuficiência Renal Crônica (IRC) atendidos pelo serviço de atendimento móvel de urgência de Rio Verde, Goiás. SALUSVITA, Bauru, v. 36, n. 1, p. 47-54, 2017.

CUPPARI, L. Guia de nutrição clínica no adulto. 3. ed. Barueri-SP: Manole, 2014.

DOBNER, T. et al. Avaliação do estado nutricional em pacientes renais crônicos em hemodiálise. Scientia Medica, v. 24, n. 1, p. 11-18, 2014.

D’AMICO, L. F. et al. Caracterização do Estado Nutricional de Pacientes com Insuficiência Renal Crônica em Programa de Hemodiálise na Cidade de Guarapuava - Paraná. Uniciências, v. 17, n. 1, p. 17-24, dez. 2013.

FERRAZ, S. F. et al. Estado nutricional e ganho de peso interdialítico de pacientes com doença renal crônica em hemodiálise. Jornal Brasileiro de Nefrologia, v. 37, n. 3, p. 306-314, 2015.

FRIZZERA, R. O. Percepções do conhecimento em noções básicas de nutrição e aplicação prática/habitual da alimentação dos portadores de doença renal crônica em tratamento de hemodiálise. 2013. 93 f. Monografia- Faculdade Católica Salesiana do Espírito Santo, Vitória, 2013.

FUKUDA, C. M.; MENDONÇA, A.; LOPES, L. C. Comparação do conhecimento nutricional de pacientes portadores de doenças crônicas não transmissíveis de acordo com aspectos sociais. Revista Corpoconsciência, Santo André, v. 17, n. 1, p. 19-29, jan/jun. 2013.

HAZIN, M. A. A. Anemia in chronic kidney disease. Revista da Associação Médica Brasileira, São Paulo, v. 66, supl.1, p. 55-58, 2020.

KOCK, K. S.; NETO, J. A. B.,; MACHADO, M. O.. Comparação do nível de atividade física e força de preensão manual com o perfil bioquímico de doentes renais crônicos. Revista Ciência e Saúde, v. 10, n. 1, p. 10-17, 2017.

MACHADO, A. D.; BAZANELLI, A. P.; SIMONY, R. F. Avaliação do consumo alimentar de pacientes com doença renal crônica em hemodiálise. Revista Ciência \& Saúde. Porto Alegre, 
v. 7, n. 2, p. 76-84, 2014.

MASSEY, D. Commentary: clinical diagnostic use of cystatin C. Journal of Clinical Laboratory Analysis, v. 18, n. 1, p. 55-60, 2004.

MELO, A. S. T.; ELIAS, M. A. R.; AGUIAR, A. S. Conhecimento do tratamento de hiperfosfatemia e adesão às orientações nutricionais após intervenção em indivíduos em hemodiálise. HU Revista, v. 45, n. 4, p. 374-80, 2019.

NERBASS, F. B. et al. Adesão e conhecimento sobre o tratamento da hiperfosfatemia de pacientes hiperfosfatêmicos em hemodiálise. Jornal Brasileiro de Nefrologia, v. 32, n. 2, p. 149-155, 2010.

NERBASS, F. B, et al. Percepções de pacientes em hemodiálise sobre as restrições alimentares, Jornal Brasileiro de Nefrologia, v. 39, n. 2, p. 154-156, 2017.

NUNES, N. B. et al. Perfil epidemiológico de pacientes renais crônicos em programa dialítico. Revista de enfermagem da Universidade Federal de Pernambuco, Recife, v. 8, n. 1, p. 6976, jan. 2014.

OLIVEIRA JÚNIOR, H. M.; FORMIGA, F. F. C.; ALEXANDRE, C. S. Perfil clínico-epidemiológico dos pacientes em programa crônico de hemodiálise em João Pessoa - PB. Jornal Brasileiro de Nefrologia, v. 36, n. 3, p. 367-374. 2014.

PORTO, J. R. et al. Avaliação da função renal na doença renal crônica. Revista Brasileira de Análises Clínicas, Rio de Janeiro, v. 49, n. 1, p. 26-35, 2017.

RIBEIRO, M. M. C. et al. Análise de diferentes métodos de avaliação do estado nutricional de pacientes em hemodiálise. Revista Cuidarte, v. 6, n. 1, p. 932 - 940, mai. 2015.

RIBEIRO-ALVES, M. A.; GORDA, P. A. Diagnóstico de anemia em pacientes portadores de doença renal crônica. Brazilian Journal of Nephrology, v. 36, n. 1, sup. 1, p. 9-12, 2014.

ROUHANI, M. H. et al. Comparison of Three Diet Quality Indices for Patients with Chronic e Kidney Disease. Archives of Iranian Medicine, v. 20, n. 8, p. 474 - 480, ago. 2017.

SCHUSTER, J. T. et al. Avaliação de sintomas depressivos em pacientes com insuficiência renal crônica submetidos à hemodiálise. Revista da Associação Médica do Rio Grande do Sul, Porto Alegre, v. 59, n. 1, p. 15-19, jan/mar. 2015.

SILVA. M,; COUTO, N. M. R. Avaliação do RDW como indicador da deficiência de ferro em pacientes com insuficiência renal crônica submetidos à Hemodiálise. Revista Brasileira de Análises Clínicas, v. 4, n. 3, p. 211-5, 2016.

SILVA, S. M. C. S.; MURA, J. D. P. Tratado de alimentação, nutrição e dietoterapia. 3. ed. São Paulo: Payá, 2016.

TEIXEIRA, F. I. R. et al. Sobrevida de pacientes em hemodiálise em um hospital universitário. Jornal Brasileiro de Nefrologia, v. 37, n. 1, p. 64-71, 2015.

TELLES, C.; BOITA, E. R. F. Importância da terapia nutricional com ênfase no cálcio, fósforo e potássio no tratamento da doença renal crônica. Revista Perspectiva, v. 39 , n. 145, p. $143-$ 154, mar. 2015.

TINÔCO, J. D. S. et al. Prurido no paciente em hemodiálise: associação com ingestão de fósforo e nível sérico de cálcio, Revista Gaúcha de Enfermagem, v. 39, 2018. 